\title{
Implementation of Lean Manufacturing Practices in the Organization of Distance Education by the Ryazan Institute (Branch) of the Moscow Polytechnic University
}

\author{
Nadezhda Zakharova ${ }^{1, *}$, Alexander Asaev ${ }^{2}$, Natalia Bryazgunova ${ }^{1}$, and Ilya Kiryushin ${ }^{3}$ \\ ${ }^{1}$ Department of Engineering Business and Management, Ryazan Institute (branch) of \\ Moscow Polytechnic University, 390000 Ryazan, Russia \\ ${ }^{2}$ Department of Mechanical and Technological Disciplines, Ryazan Institute (branch) of \\ Moscow Polytechnic University, 390000 Ryazan, Russia \\ ${ }^{3}$ Department of Automobiles and Transportation and Technological Means, Ryazan \\ Institute (branch) of Moscow Polytechnic University, 390000 Ryazan, Russia
}

\begin{abstract}
The transition to new formats of education interprets the need for us to search for new methods of managing educational organizations. In recent years, more and more attention has been paid to lean manufacturing as one of the most effective management methods. After all, it is the introduction of lean manufacturing that will allow us to form a management concept based on a constant striving to improve all processes occurring within educational institutions and eliminate all types of losses. Also, lean production involves the involvement of each employee in the optimization process and maximum focus on the end consumer, that is, applicants and their parents. One of the directions is the creation of a completely new model of university management - the model of "change management". Change management is designed to help any educational institution find a way out of this situation, to promote the formulation and implementation of the set goals of a new level, which are designed to positively influence the emotional component of the team, which ensures the conditions for the breakthrough development of the university through digitalization of all aspects of activity for the transition to competitive educational and scientific -the research model.
\end{abstract}

\section{Introduction}

The situation with the pandemic occurring all over the world made scientists from all over the world think about how to deal with these conditions, how to preserve enterprises and organizations, how to retain staff and, most importantly, work and earn money. This problem also affected educational institutions. Considering in more detail this particular sector of the economy, we tried to identify what is happening with universities. The

\footnotetext{
*Corresponding author : nad2246@mail.ru
} 
primary problem was the lack of readiness to switch to remote forms of work. This problem may have several reasons: there are no clear goals, no final vision of the result, that is, what exactly does the leadership want and how teachers should carry out their work. The second reason was the low motivation and interest of staff in achieving goals. The third reason was "fear in the future". When the country's leadership announced a self-isolation regime and issued an order to close educational institutions and transfer them to distance learning, most of the staff panicked, fearing layoffs and a decrease in income [1].

It should also be noted that with the transition to the remote form of teaching work among teachers and employees of enterprises from other industries, an increase in the level of stress is observed.

All of the above dictates the search for new management methods. One of the most effective, from our point of view, management methods can be the introduction of the principles and tools of lean production.

\section{Methodology}

The relevance of the research topic is determined by the fact that the it is the introduction of lean manufacturing that will allow us to form a management concept based on a constant striving to improve all processes occurring within educational institutions and eliminate all types of losses. Also, lean production involves the involvement of each employee in the optimization process and maximum focus on the end consumer, that is, applicants and their parents.

This topic is actively disclosed by groups of authors in their works, articles and monographs. The main results of the implementation of lean manufacturing in universities are presented in the scientific works of Davydova N.S., Kuizheva S.K., Polukhin O.N., Sharafanova E.E., Fedosenko Yu.A., Batayev A.V., Polyakov K.I., Avilkina S.V.

In order to assess how effective the proposed model of lean production in higher educational institutions is, it is necessary to use an integrated method that will contain not only a literature review, but also the results of group discussion, but also methods of observation, description, experiment and comparison [2].

Thus, we have come to the need to create a completely new model of university management - the model of "change management". Change management is designed to help any educational institution find a way out of this situation, to promote the setting and implementation of the set goals of a new level, which are designed to positively influence the emotional component of the team, reduce staff resistance and activate the growth of staff involvement, which in turn will allow us to achieve the desired result. namely, the provision of conditions for the breakthrough development of the university through the digitalization of all aspects of activities for the transition to a competitive educational and research model.

\section{Goals and objectives of implementing lean manufacturing practices in the organization of distance education}

During the implementation of the Lean Manufacturing project, a scientific community was created at the university, which included students and teachers. Within the framework of this community, visits were organized to all kinds of lectures and forums on Lean Manufacturing, organized by the Center for Lean Manufacturing of the Ryazan Region.

To determine the vector in accordance with which we plan to move and determine a specific project, it is necessary to determine the goals and objectives of the Ryazan Polytechnic Institute, then to determine the goals and objectives of the project. Since the 
effectiveness of this campaign will depend on the coordination of actions and the absence of contradictions in the activities of the management of the institute and the implementation of the project.

Analyzing the activities of the Ryazan Polytechnic Institute, the following goals and objectives of the development strategy were identified:

- Implementation of the digital institute model;

- Development of new educational technologies;

- Creation of a comfortable environment for the institute;

- Development of a system for training highly qualified personnel;

- Establishment of a system for the development of human resources for the teaching staff;

- Creation of a unified system of work in the pre-university sector;

- Development of scientific and engineering competencies;

- Development of cooperation with government bodies, nonprofit organization and business in the framework of the implementation of urgent social and economic projects.

These goals and objectives are satisfied by the following areas of activity, within the framework of which we have formulated the following projects:

1. "Formation of a pre-professional educational environment";

2. "Development of online education";

3. "Development of scientific competencies and scientific reputation";

4. "Effective management structure";

5. "Digital Institute".

The "Digital Institute" project combines infrastructure tasks and tasks of providing remote access to the results of other projects and is thus a top-level one.

The aim of the project is to provide conditions for the breakthrough development of the university through digitalization of all aspects of activities for the transition to a competitive educational and research model of activity [3]. result:

This goal forms the following list of tasks, which is necessary to obtain the planned

- creation of a stable and secure information and telecommunications infrastructure for high-speed transmission, processing and storage of large amounts of data;

- use of mainly domestic software;

- ensuring the global competitiveness of the Ryazan Polytechnic Institute;

- creation of a modern and safe digital educational environment, ensuring high quality and accessibility of education of all types and levels by 2027 ;

- introduction of a national system of professional development of teaching staff;

- modernization of vocational education, including through the introduction of adaptive, practice-oriented and flexible educational programs.

Additionally, the project is designed to solve some of the general tasks of the Moscow Polytechnic University:

- Creation of the environment and conditions necessary for the development and implementation of digital technologies;

- Improving the quality of the final product of the institute (education and research).

\section{Practical implementations of the project}

Taking into account the principles laid down in the Digital University model, we will try to form a list of technologies and solutions, the implementation of which will lead to the achievement of the greatest effect in the digital development of the university:

1. Provision of wireless access to data transmission networks in the places of stay of 
students on the territory of the Institute.

2. Formation of infrastructure for the development of a digital educational environment: equipping classrooms with content visualization tools and equipping teachers with devices for working with digital resources.

3. Ensuring comfortable use by students and employees of their own devices to access the information resources of the university and visualization tools with the support of group work.

4. Distributed printing system for students and employees.

5. Cloud storage services.

6. Digital library infrastructure based on free access to information.

7. Ensuring the requirements for the protection of information in the information infrastructure of the university.

8. Management of activities for the provision of IT services based on the principles of ITSM in order to facilitate the interaction of stakeholders (users) with technology.

9. Comfortable access to specialized software for education and research activities both in computer classes and on students 'and teachers' own devices.

10. Digital Learning Environment (LMS) focused on supporting blended learning and distance education and supporting the creation of digital educational content and online courses.

11. An integrated information system of administrative and economic activities (ERPsystem), aimed at improving the efficiency of resource management and ensuring full electronic interaction of departments within the framework of end-to-end business processes.

12. Admission to the university "in one click": a high-tech process of applying, paying, enrolling, gaining access to educational resources and confirming the knowledge gained.

13. Ensuring the interaction of the institute with the student and teacher in electronic form, except for cases where the presence of a paper document is established by the requirements of the legislation. At the same time, the information necessary for the activities of the university comes from students and employees in electronic form, at the request of the relevant services. There is development of electronic document flow between departments and external correspondents (without duplication on paper) [4].

14. Implementation of digital marketing - organizing interaction with applicants, students, graduates using the entire range of digital communication channels to implement the principle of "offering redundant information to a potential consumer."

15. Formation of digital skills (the ability to use technology in everyday work) of students and staff at the university, which is part of the ecosystem of the digital economy.

The funding sources for this project are:

1. Own funds of the Institute;

2. Funding under the federal project "Human Resources for the Digital Economy".

However, during the implementation of the proposed project, certain difficulties may arise, which also need to be considered and try to minimize them at all stages of the project development. These risks include:

1. Decrease in funding for project activities;

2. Failure of obsolete legacy infrastructure elements;

3. Lack of motivation of the staff of the institute to change;

4. Incorrect choice of technological solutions for implementation;

5. Late provision of requirements for new services from strategic project managers.

This project provides a proactive response to the requests of students, teachers and employees in the field of information and communication technologies.

In the course of the project, design and working documentation for information systems, services and infrastructure complexes is being developed. 
Let us consider the impact of the project results on the performance indicators of the institute presented in Table 1.

Table 1. Impact of the project results on the activities of the Ryazan Polytechnic Institute

\begin{tabular}{|l|l|c|}
\hline № & \multicolumn{1}{|c|}{ Institute development program indicator } & \multicolumn{1}{|c|}{$\begin{array}{c}\text { Impact of the } \\
\text { project }\end{array}$} \\
\hline 1 & $\begin{array}{l}\text { The share of online courses in the total number of } \\
\text { educational programs implemented by the university. }\end{array}$ & average \\
\hline 2 & $\begin{array}{l}\text { Satisfaction with the conditions of work organization and } \\
\text { the equipment of workplaces. }\end{array}$ & average \\
\hline 3 & $\begin{array}{l}\text { The degree of satisfaction with the condition and } \\
\text { equipment of the classrooms with modern technical } \\
\text { means. }\end{array}$ & high \\
\hline 4 & Satisfaction with the management system & \\
\hline
\end{tabular}

Having considered how the project can positively affect the development of the university, you can proceed to a more detailed study of it.

From our point of view, the project implementation plan should include 5 blocks:

1. Block "Infrastructure";

2. Block "Digital Education";

3. Block "Digital Interaction";

4. Block of events "Digital Marketing";

5. Block "Building up complementary ICT skills of the Institute staff."

In the life of modern society, education plays one of the main roles, since it is the main source of generation, improvement and development of human capital, and, consequently, a resource for the socio-economic development of countries, the progress of society and an increase in the well-being of an individual. In connection with the constant and rapid updates of technologies, mainly information, transformation processes in the social sphere, significant changes are taking place in the field of education in the world and in Russia.

To this end, we have developed a strategy for the development of educational technologies, which we begin to implement in 2020 and plan to implement until 2027.

The transformation of education, from our point of view, should contain the following directions, which are presented in the table 2 .

The mission of this strategy, from our point of view, should be to open up new opportunities for the harmonious development of a competitive personality and inspire to solve more global problems.

The strategic goal is the generation of new knowledge, markets and businesses, human navigation in the world of information, providing a balance of physical and virtual reality.

To realize the purpose formed by the mission and purpose, it is possible to single out the mandatory presence and implementation of the following elements:

1. Value - respect for the individual, conscientiousness, academic freedom, openness, love.

2. Fundamentality - systemic, analytical, critical thinking; digital culture and competencies; entrepreneurial culture and competencies; design thinking.

3. Professional competencies - quality of training, professions of the future, individual trajectories.

4. Over-subject competencies - creativity, communication, leadership, emotional intelligence, team solving of complex problems. 
Table 2. Institute 2027: transformation of education

\begin{tabular}{|c|c|c|}
\hline \multicolumn{3}{|c|}{ from 2020 to 2027} \\
\hline Teacher -lecturer & C & $\begin{array}{l}\text { Teacher - practitioner, expert, digital } \\
\text { navigator }\end{array}$ \\
\hline $\begin{array}{l}\text { Applicants - graduates of schools } \\
\text { and institutes }\end{array}$ & 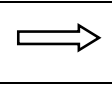 & $\begin{array}{l}\text { Applicants seeking knowledge and } \\
\text { competencies throughout their lives }\end{array}$ \\
\hline $\begin{array}{l}\text { Specialization and tough } \\
\text { educational program }\end{array}$ & ᄃ & $\begin{array}{l}\text { Variety of educational tracks: dual } \\
\text { specialization, mini-specialization, } \\
\text { additional competencies }\end{array}$ \\
\hline $\begin{array}{l}\text { Student perceives information } \\
\text { passively }\end{array}$ & 드 & $\begin{array}{l}\text { Learning in active interaction: the student } \\
\text { creates information, is a co-teacher }\end{array}$ \\
\hline $\begin{array}{l}\text { Teaching model: lectures, } \\
\text { seminars, laboratory work }\end{array}$ & ㄷ & $\begin{array}{l}\text { Mixed learning, customized trajectories, } \\
\text { student co-developers MOOCs, networked } \\
\text { learning }\end{array}$ \\
\hline $\begin{array}{l}\text { A graduate is looking for work in } \\
\text { his specialty }\end{array}$ & ㄷ & $\begin{array}{l}\text { A graduate creates work for himself and } \\
\text { others }\end{array}$ \\
\hline $\begin{array}{l}\text { Diploma in an accredited } \\
\text { direction }\end{array}$ & $\Longrightarrow$ & $\begin{array}{l}\text { Diploma / Professional Certification / } \\
\text { Graduate Digital Portfolio }\end{array}$ \\
\hline
\end{tabular}

\section{Conclusion and prospects}

Lean implementation is just getting started. When digitalization will more closely enter our lives, then we will be able to talk about a fundamentally new education system, but for this it is necessary to have a sufficiently strong foundation, which we are just beginning to create. Achieving it is possible, including on master's programs, and on narrow-profile programs of additional professional education dedicated to digital skills.

\section{References}

1. European Opera Digital Project Royal Opera House Cooperation Projects England 2014. http://www.creativeeuropeuk.eu/fundedprojects/european-opera-digital-project2

2. Sharafanova E.E., Fedosenko Y.A., Skhvediani A.E. Journal of Advanced Research in Law and Economics. Volume 8, Issue 6, Fall 2017. Pages 1908-1915 (2017)

3. Bataev A.V. 2017. Electronic learning as the condition of improvement in quality of learning of engineering and economic personnel. Proceedings of 2017 |EEE 6th Forum Strategic Partnership of Universities and Enterprises of Hi-Tech Branches (Science Education. Innovation), SPUE 2017. Volume 2018 - January, 1 January 2017, Pages 103-106

4. Malevskaia-Malevich E.D., Leonov S.A., Denis Z. 2018. Quality management in scientific and education organizations: Methods and tools. Proceedings of the 31st International Business Information Management Association Conference, IBIMA 2018: Innovation Management and Education Excellence through Vision 2020. 2018, Pages 5614-5619. 